International Journal on Web Service Computing (IJWSC), Vol.3, No.1, March 2012

\title{
Web Services Supply Chains: A Literature Review
}

\author{
Krithika V ${ }^{1}$, Dr. Arshinder Kaur ${ }^{2}$ and Dr. K. Chandra Sekaran ${ }^{3}$ \\ ${ }^{1}$ Department of Management Studies, Indian Institute of Technology Madras, India \\ krithika1288@gmail.com \\ ${ }^{2}$ Assistant professor, Department of Management Studies, Indian Institute of Technology \\ Madras, India \\ arshinder@gmail.com \\ ${ }^{3}$ Professor, Department of Computer Science Engineering, National Institute of \\ Technology, Surathkal, India \\ kchnitk@gmail.com
}

\section{Introduction}

The globalization era has bought almost all services to the internet environment with multiple providers providing the same service in different ways. The same functionality is being offered by multiple providers so it becomes necessary to differentiate one self from the crowd in order to thrive against the cut throat competition from the service provider's view. On the other hand it is absolutely essential for the client to select a service provider who meets not only the functional requirements of the client but also provides the best possible quality of service (QoS) to the customers. The services industry has contributed approximately 55.3\% to the GDP of India in the year 2009. The service sector employs about $34 \%$ of the labor force in India [CIA report]. The exponentially growing service industry has started making its global presence through the internet enabled online environment. The web environment has made almost all kind of services available online be it a simple movie ticket booking or the most complex processes such as outsourcing, funds transfer and others. The online services are special kind of services as compared to the static or product supply chain which is more offline or the semi online service supply chains in which part of the service is offline and partly online.

The objective of this paper is to present a literature review about web services supply chains and the non - functional or QoS attributes consideration in them. The web service non - functional attributes considered in the literature so far, the methodologies used the perspectives of consideration and the topics considered till now. The outcome is to point out the research gap as far as web services supply chains and the QoS aspects of web services supply chains are considered and possible future research work. 


\section{Online service supply chains and the web service ecosystem}

\section{A. Defining service supply chains:}

The service supply chain literature till now considers static services/services allied to a manufacturing product and semi - online services where a part of service takes place online and remaining takes place offline. The pure online services / web services on the other hand involve service delivery by the dynamic collaboration of multiple entities in the internet environment. The simple definition of web services come from Krishnan et al., 2009, which defines web services as a service offered as a software. The collaboration is many times not a pre- defined or fixed one it involves selection from a pool of service providers and intermediate providers based on a virtual run time contract. The service selection, service providing and acceptance are instantaneous and dynamic. The service supply chain is defined as, an integration of a series of entities (individual person, organization, enterprise) to provide personalized service directly or indirectly (Bo et al, 2010, Huaqing et al., 2009). This definition when coupled with the internet environment makes the service supply chain more dynamic. The dynamism makes these supply chains more different from the service supply chains definitions in the literature. The advent of advanced concepts like service oriented architecture SOA and web services have made the dynamic collaboration possible (Hillegersberg. et al., 2004). The indulgence of SOA and web services resulted in the web service ecosystem defining the participants of online service supply chains (Singh. et al., 2005). The web eco system has three main entities namely the service provider, intermediate and the client/ customer.

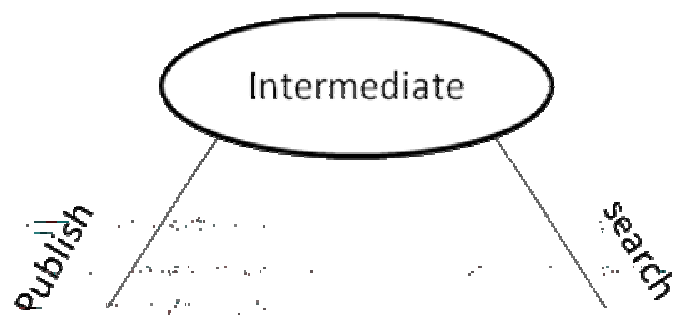

Fig 1: Web service ecosystem

The intermediate can be either other service providers or just brokers. The brokers can be of two types namely forwarding broker and match making broker. The forwarding brokers play the role of plumbing between the service provider and the client through which the client communicates with the service provider to get the service. The match making broker on the other hand just act like match makers in the real world they just connect the service providers and clients acting like a common connecting point (Sukkar ,2010). The performance of the eco system depends on all the three entities but in case of matchmaking broker type ecosystem the performance of the broker will not affect the ecosystem much because the broker just acts as the connecting point. 
B. Comparison of service supply chains with manufacturing supply chains

The properties that differentiate service supply chains from product oriented / manufacturing supply chains are,

i. Perish ability: A service perishes once it is not consumed on time i.e the service cannot be reused later e.g. A flight's empty seat after the take off of the airplane is a loss since it has already perished

ii. Simultaneity: Services must be consumed simultaneously at the time of production since they cannot be inventoried or stored

iii. Intangibility: Services are mostly not physical i.e. tangible they are intangible because they are either experience oriented or meant for individual demands.

iv. Non - transferability: The services are non transferable due to the lack of ability to be inventoried.

These characteristics are based on the literature (Bo et al, 2010, Huaqing et al., 2009) on service supply chains till now which is very limited in nature.

\section{Research methodology}

\section{A. Journals and Conferences}

The literature review presented here is based on the exploratory study of literature from various prestigious international journals and conferences. The journals and conferences considered for the literature review include the following,

\begin{tabular}{|c|c|c|c|c|}
\hline Publication & Total & $\begin{array}{l}\text { Conference } \\
\text { Papers }\end{array}$ & $\begin{array}{l}\text { Journal } \\
\text { Papers }\end{array}$ & $\begin{array}{l}\% \text { over total } \\
\text { number of } \\
\text { papers }\end{array}$ \\
\hline IEEE & 55 & 44 & 11 & 44.35 \\
\hline Elsevier & 8 & 0 & 8 & 6.45 \\
\hline Emerald & 4 & 0 & 4 & 3.23 \\
\hline $\begin{array}{l}\text { International Journal of web } \\
\text { service research }\end{array}$ & 5 & 0 & 5 & 4.03 \\
\hline $\begin{array}{l}\text { International Journal of web } \\
\text { service practices }\end{array}$ & 4 & 0 & 4 & 3.23 \\
\hline $\begin{array}{l}\text { Journal of Computers and System } \\
\text { Sciences }\end{array}$ & 4 & 0 & 4 & 3.23 \\
\hline Journal of Simulation & 3 & 0 & 3 & 2.42 \\
\hline Information Technology Journal & 5 & 0 & 5 & 4.03 \\
\hline Other journals / Conferences & 36 & 4 & 32 & 29.03 \\
\hline Total & 124 & 48 & 76 & \\
\hline
\end{tabular}

Table1. List of references

The contribution in terms of the number of journals and conferences include areas such as web service's non-functional aspects, method of consideration of non- functional attributes, web 
services and service oriented architectures in enabling service supply chains, service oriented supply chains.

\begin{tabular}{|c|c|c|c|c|}
\hline Topics & Total & $\begin{array}{l}\text { Conference } \\
\text { papers }\end{array}$ & Journal Papers & $\begin{array}{l}\% \text { over } \\
\text { total } \\
\text { number of } \\
\text { papers }\end{array}$ \\
\hline $\begin{array}{l}\text { Broker based web services selection } \\
\text { with QoS }\end{array}$ & 4 & 3 & 1 & 5.71 \\
\hline $\begin{array}{l}\text { Business service networks (SOA and } \\
\text { web services for supply chains) }\end{array}$ & 5 & 3 & 2 & 7.14 \\
\hline Web service selection with QoS & 9 & 3 & 6 & 12.86 \\
\hline Web service discovery with QoS & 3 & 1 & 2 & 4.29 \\
\hline Web service QoS monitoring/support & 5 & 5 & 0 & 7.14 \\
\hline Web service composition with QoS & 14 & 4 & 10 & 20.00 \\
\hline $\begin{array}{l}\text { Non - functional properties / QoS of } \\
\text { web services }\end{array}$ & 13 & 12 & 1 & 18.57 \\
\hline $\begin{array}{l}\text { Survey/ Classification of QoS } \\
\text { properties }\end{array}$ & 3 & 3 & 0 & 4.29 \\
\hline $\begin{array}{l}\text { Service oriented architecture (SOA) } \\
\text { for supply chains }\end{array}$ & 9 & 5 & 4 & 12.86 \\
\hline Service supply chains & 3 & 3 & 0 & 4.29 \\
\hline $\begin{array}{l}\text { Supply chains as collborative } \\
\text { networks }\end{array}$ & 2 & 2 & 0 & 2.86 \\
\hline Total & 70 & 44 & 26 & \\
\hline
\end{tabular}

\section{B. Classification topics:}

The topics are considered in such a way so as to investigate the relationship among the enablers of service supply chains, the non-functional aspects of online services considered so far in the literature thus moving from lower to higher level of abstraction while classifying the literature. The classification we present concentrates more on the web services and their non- functional properties/ QoS aspects and service supply chains. 


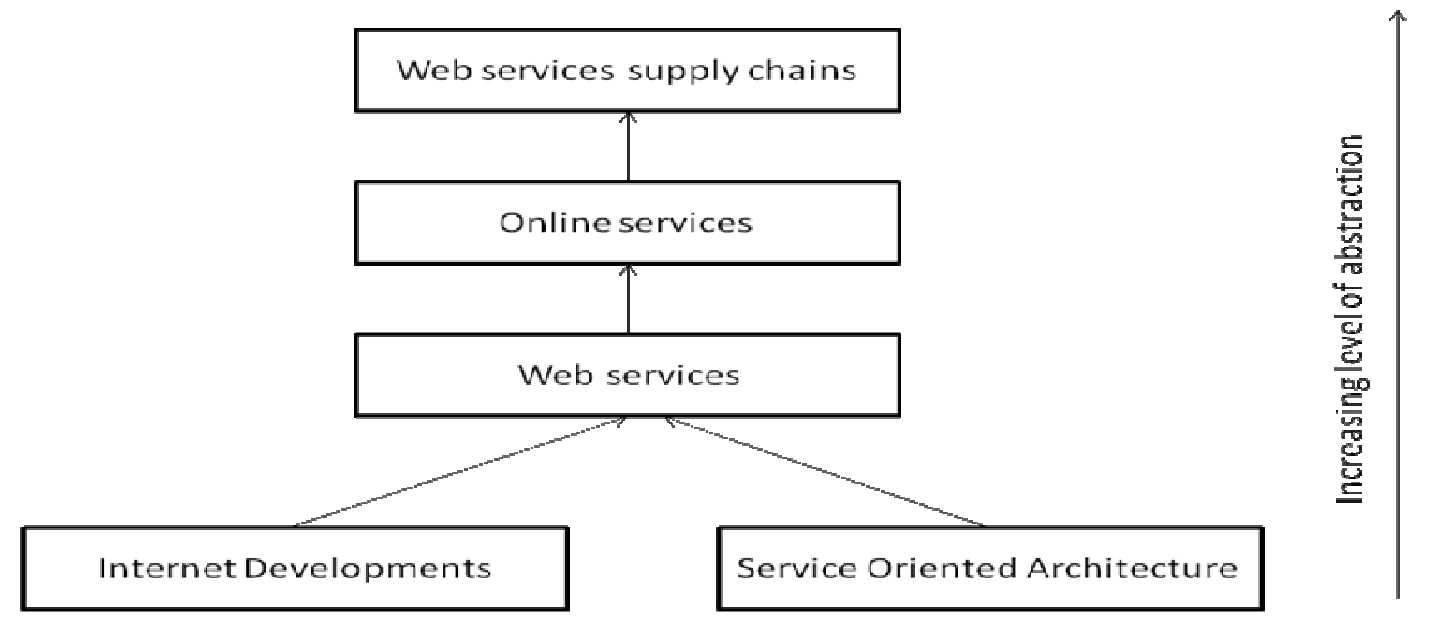

Fig 2. Classification based on topic

Table 2. Classification based on topic

The literature review process how ever considers the literature related to service oriented architecture's (SOA) role in enabling web services (Carey, 2008, Heuvel et al., Dubey et al., Casola et al.,2007 Singh , 2000), SOA's applicability to supply chains in enabling automation, collaboration and integration of supply chains (Qiu et al., 2006, Jin et al., Fuquan et al., 2007, Barata et al., Rung et al., 2009) and so the classification is done on topics in each aspect as shown in fig 2.

The literature classification based on various topics considered so far shows that the research has concentrated on web service composition and selection while considering QoS predominantly. The non functional properties or QoS aspects of web services have gained importance because it is necessary to differentiate a web service which is in turn a pure service (Krishnan et al., 2009) based on quality when multiple providers of same functionality are present. The automation of manufacturing supply chain has gained importance due to the expansion of industries and need to cater to global demand and compete globally. The advent of SOA and web services has resulted in middle wares and broker based architectures to be routes of QoS negotiation between service providers and clients. There is scanty amount of work in the area of service supply chains in general irrespective of semi- static or pure online services supply chains and their collaboration. The combination of SOA and web services has started to pave way for a new class of research study called the business service networks that majorly collaborate in the internet environment. How ever the research in this area is very less as it can be seen from Table 2.

\section{Classification based on Perspectives}

The use of SOA and web services brings into light the need to consider the service supply chain entities namely the service provider, intermediaries and the client (Singh 2000). The perspectives all these three participating entities must be considered and the benefit for each of these entities must be taken into account. The perspective of each entity must be analyzed and maximum gain 
for each must be identified and balanced without affecting the interest of another entity. This makes it necessary to look at the literature interns of the perspectives of the participating entities to get a clear picture of the state of the art research in this dimension.

\begin{tabular}{|l|r|r|r|r|}
\hline Perspective & Total & $\begin{array}{l}\text { Conference } \\
\text { Papers }\end{array}$ & $\begin{array}{l}\text { Journal } \\
\text { Papers }\end{array}$ & $\begin{array}{l}\text { \% over total } \\
\text { number of papers }\end{array}$ \\
\hline Client / Customer view & 28 & 12 & 16 & 35.44 \\
\hline Service provider view & 34 & 24 & 10 & 43.04 \\
\hline Middle wares & 5 & 5 & 0 & 6.33 \\
\hline $\begin{array}{l}\text { Mutual view (service provider } \\
\text { and client) }\end{array}$ & 3 & 2 & 1 & 3.80 \\
\hline $\begin{array}{l}\text { Generic (applicability of } \\
\text { concepts) }\end{array}$ & 9 & 6 & 3 & 11.39 \\
\hline Total & 79 & 49 & 30 & \\
\hline
\end{tabular}

Table 3. Classification based on perspective

The classification clearly shows that the research till now pertains to one of the participating entities predominantly the clients and the service providers. The research works considering the participating entities' effect on each other, the conflict of interests that might arise, how the performance of one entity affects the collective performance, the optimal gain possible for all the entities and other related questions are scarce. The middle wares how ever have started gaining research focus but the mutual consideration is still taking a back seat in terns of the research work.

\section{Classification based on methods}

The method used in a research decides the perspective and objective of a research work. The methods range from very old ones to brand new ones with many new dimensions to the research problem and tradeoffs for each method used. The classification based on methods is shown below in table 4. The classification clearly shows that conceptual work, ontology and frame works have got lot of research attention. There is how ever equal amount of mathematical formulation and prototyping/ implementation methods used to prove the concepts proposed. The use of automata theory to handle time properties is gaining importance. The extension of this is the latest use of petrinets to verify time properties of online services. The need to incorporate client requirements and suggestions has started getting attention with the use of methods like quality function deployment, fuzzy logic and neural networks approaches that help to convert subjective user inputs to objective values that can be used for further analysis to take appropriate actions.

\begin{tabular}{|c|c|c|c|c|}
\hline Method & Total & Conference Papers & $\begin{array}{l}\text { Journal } \\
\text { Papers }\end{array}$ & $\begin{array}{l}\% \text { over total } \\
\text { number of } \\
\text { papers }\end{array}$ \\
\hline Petri nets & 4 & 1 & 3 & 5.33 \\
\hline Fuzzy logic/ Neural networks & 4 & 2 & 2 & 5.33 \\
\hline Quality Function Deployment & 2 & 1 & 1 & 2.67 \\
\hline
\end{tabular}


International Journal on Web Service Computing (IJWSC), Vol.3, No.1, March 2012

\begin{tabular}{|l|r|r|r|r|}
\hline Timed Automata & 3 & 3 & 0 & 4.00 \\
\hline Ontology & 13 & 9 & 4 & 17.33 \\
\hline Architectures and Frame work & 20 & 13 & 7 & 26.67 \\
\hline Graphs & 2 & 1 & 1 & 2.67 \\
\hline Conceptual & 10 & 6 & 4 & 13.33 \\
\hline $\begin{array}{l}\text { Mathematical formulation and } \\
\text { analysis }\end{array}$ & 8 & 5 & 3 & 10.67 \\
\hline Implementation and Prototyping & 9 & 5 & 4 & 12.00 \\
\hline Total & 75 & 46 & 29 & \\
\hline
\end{tabular}

Table 4a. Classification based on methods

The research how ever points out that the collaborating service entities in the web environment form a logical graph rather than a traditional client server link (Chan et al., 2005) but the research methods with graphs is very scanty compared to the other methods that have been used till now. The combinations of some methods such as fuzzy logic and quality function deployment (Zhu et al., 2010) are used together to get better results. The advent of programming languages and ease of programming has led to the increase in prototyping and implementation of concepts easily. The operations research (OR) methods applied in this research area are shown below in table $4 \mathrm{~b}$.

\begin{tabular}{|c|c|c|c|c|}
\hline Operations research methods used & Total & $\begin{array}{l}\text { Conference } \\
\text { Papers }\end{array}$ & $\begin{array}{l}\text { Journal } \\
\text { papers }\end{array}$ & $\begin{array}{l}\% \text { over total number of } \\
\text { papers }\end{array}$ \\
\hline Genetic Algorithm & 2 & 2 & 0 & 18.18 \\
\hline $\begin{array}{l}\text { Optimization (Linear } \\
\text { programming, Mixed Integer } \\
\text { programming) }\end{array}$ & 3 & 0 & 3 & 27.27 \\
\hline Simulation & 4 & 2 & 2 & 36.36 \\
\hline $\begin{array}{l}\text { Multi-criteria decision making } \\
\text { and Analytical hierarchy Process }\end{array}$ & 2 & 0 & 2 & 18.18 \\
\hline Total & 11 & 4 & 7 & \\
\hline
\end{tabular}

Table 4b. Classification based on OR methods

The classification based on OR methods clearly show that very few methods are used in the current area of research. The use of simulation and optimization is higher compared to other OR methods used. The use of methods like genetic algorithms is reported to have problems of computational complexity and local maxima how ever better versions of genetic algorithms relevant to the problem may give near optimal solutions in many cases. In the context of selection among multiple choices based on multiple factors/criteria multi - criteria decision making methods are very useful but almost all multi- criteria methods suffer from the problem of deciding the correct weights for the factors/ criteria under consideration. The use of methods like analytical hierarchy process is enormous when it is needed to rank the service providers from the available pool based on the user preferred criteria. The case of web service supply chains considering all the participating entities and optimizing for all to reach their objectives OR 
methods like goal programming, dynamic programming and other methods might be of great help in taking the problem towards solution.

\section{E. Classification based on attributes}

The need for non - functional attributes or QoS in a web environment is enormous due to multiple competitors providing the same functionality. The QoS attributes act as order winners for the service providers. There are a large number of QoS attributes and the QoS attribute most important for a service is dependent on the user requirements and the type of the service itself. The QoS attributes are how ever considered individually in the literature rather than being considered together. The classification based on the non - functional attributes is presented below in table 5a as shown. The classification itself shows the various QoS attributes possible for web services.

\begin{tabular}{|c|c|c|c|c|}
\hline Attribute & Total & Conference Papers & Journal Papers & $\begin{array}{l}\text { \% over total } \\
\text { number of } \\
\text { papers }\end{array}$ \\
\hline Reliability & 11 & 8 & 3 & 18.97 \\
\hline Latency & 2 & 1 & 1 & 3.45 \\
\hline Availability & 7 & 4 & 3 & 12.07 \\
\hline Execution time & 1 & 1 & 0 & 1.72 \\
\hline Security & 2 & 1 & 1 & 3.45 \\
\hline Safety & 1 & 1 & 0 & 1.72 \\
\hline Throughput time & 3 & 2 & 1 & 5.17 \\
\hline Response time & 2 & 1 & 1 & 3.45 \\
\hline Time & 8 & 4 & 4 & 13.79 \\
\hline Performance & 3 & 3 & 0 & 5.17 \\
\hline Usability & 2 & 2 & 0 & 3.45 \\
\hline Reputation & 2 & 2 & 0 & 3.45 \\
\hline Responsiveness & 1 & 0 & 1 & 1.72 \\
\hline Completion time & 1 & 1 & 0 & 1.72 \\
\hline Mean peak period latency & 1 & 1 & 0 & 1.72 \\
\hline Success of completion & 3 & 1 & 2 & 5.17 \\
\hline Cost & 4 & 1 & 3 & 6.90 \\
\hline Accessibility & 1 & 1 & 0 & 1.72 \\
\hline Capacity & 1 & 1 & 0 & 1.72 \\
\hline $\begin{array}{l}\text { MTBF (Mean time before } \\
\text { failure), MTTR (Mean time } \\
\text { to recover) }\end{array}$ & 2 & 2 & 0 & 3.45 \\
\hline Total & 58 & 38 & 20 & \\
\hline
\end{tabular}

Table 5a. Classification based on QoS attributes 
The table clearly points out that there has not been even consideration of the QoS attributes as far as literature is concerned. The major research literature relating to QoS attributes focus on few parameters like reliability, availability and time in general. The literature how ever has each of these terms defined and represented mathematically.

\begin{tabular}{|c|c|}
\hline Attributes & Author(s) \\
\hline Accessibility & Mathias et al., 2008; Yoem et al., 2006; \\
\hline Availability & $\begin{array}{l}\text { Menasce, 2002; Tian et al., 2008; Mathias et al., 2008; Sullivan 2005; } \\
\text { Maheswari et al., 2005; Bentallah et al., 2004; Zhang et al., 2005; } \\
\text { Seyyedi et al., 2010; Li et al., 2010; Yoem et al., 2006; Ran 2003; }\end{array}$ \\
\hline Capacity & Mathias et al., 2008 \\
\hline Completion time & Lammanna et al., 2003 \\
\hline Cost & Sullivan 2005; Li et al., 2010; Gorson et al., 2008 \\
\hline Execution time & Bentallah et al., 2004; Li et al., 2010; \\
\hline Latency & Raimondi et al., 2007 \\
\hline $\begin{array}{l}\text { Mean peak period } \\
\text { latency }\end{array}$ & Lammanna et al., 2003 \\
\hline Performance & Zhang et al., 2005; Kalepu et al., 2004; Mathias et al., 2008; Ran 2003 \\
\hline Realiabilty & $\begin{array}{l}\text { Menasce, 2002; Tian et al., 2008; Mathias et al., 2008; Raimondi et al., } \\
\text { 2007; Strunk 2010; Maheswari et al., 2006; Li et al., 2010; Basu et al., } \\
2010\end{array}$ \\
\hline Reputation & Kalepu et al., 2004; Bentallah et al., 2004; Gorson et al., 2008 \\
\hline Response time & Menasce, 2002; Tian et al., 2008; Seyyedi et al., 2010; \\
\hline Security/Safety & $\begin{array}{l}\text { Menasce, 2002; Tian et al., 2008; Casola et al., 2007; Basu et al., 2010; } \\
\text { Gorson et al., } 2008\end{array}$ \\
\hline $\begin{array}{l}\text { Success of } \\
\text { completion }\end{array}$ & Lammanna et al., 2003; Yoem et al., 2006; \\
\hline Throughput time & Menasce, 2002; Tian et al., 2008 \\
\hline
\end{tabular}


International Journal on Web Service Computing (IJWSC), Vol.3, No.1, March 2012

\begin{tabular}{|l|l|}
\hline Time & $\begin{array}{l}\text { Del val, 2009; Casola et al., 2007; Sullivan 2005; Kazhamiakin et al., } \\
\text { 2006; Zhang et al., 2005; Liu et al., 2008 }\end{array}$ \\
\hline Usability & Mathias et al., 2008; Wen et al., 2009 \\
\hline Work load & Menasce, 2002 \\
\hline
\end{tabular}

Table 5b QoS attributes literature

The table $5 \mathrm{~b}$ points out the need to consider the QoS attributes more rigorously rather than concentrating on selected few QoS attributes. The need to concentrate evenly on all QoS attributes is because these QoS attributes can be grouped into customer related and service provider related QoS attributes as shown below in table 5c.

\begin{tabular}{|l|l|}
\hline Customer & Service provider \\
\hline Reliability & $\begin{array}{l}\text { Success of completion Mean time before failure/ } \\
\text { MTBF }\end{array}$ \\
\hline Availability & Security \\
\hline Usability & Safety \\
\hline Accessibility & Capacity \\
\hline Reputation & Performance \\
\hline & Cost \\
\hline Time & Throughput time \\
\hline & Response time/Latency \\
\hline & Completion time \\
\hline & Execution time \\
\hline
\end{tabular}

Table 5c. Grouping of QoS attributes into client and service provider related QoS

The QoS attributes on client column shows the QoS attributes that the clients considered being most important to select a service and the QoS attributes in the service provider side show how the client perceived QoS translates to the service provider. The research making use of this relationship does not exist to the best of our knowledge. This is a huge research gap that might answer many QoS related questions in the web service supply chains context.

\section{Research gaps}

There is a huge gap in terms of the concept of web services supply chains, the QoS attributes, the mutual optimization based on the requirements of all participating entities. The gap needs to be addressed effectively and efficiently.

a. Conceptual gap:

There is a lack of definition of web services supply chain concept though there are definitions for many of the enablers and drivers of the web services supply chains. The defining of roles in a 
web services supply chains, the interaction among the entities and the issues related to this kind of pure service supply chain.

b. QoS / non - functional requirements gap:

The need for quality in web services supply chains is essential in order to differentiate from the crowd as pointed out earlier. The entities participating in a particular service delivery is not known so considering QoS attributes individually might night help since the web service supply chain is affected by individual bad performance to a higher degree than that of a static/ semi static supply chains. A way of consolidating the QoS attributes is necessary for fixing minimum QoS requirements that each participating entity must satisfy and for easier QoS calculations.

c. Mutual optimization methods:

The mutual optimization for all entities considering each one's constraints, requirements, capabilities and considering how each entity's good / bad performance adds/ affects the others is needed. This kind of optimization is very complicated since it involves multiple view points and requirements. Some suitable methods for this kind of optimization is to be put forward to resolve this gap.

\section{Conclusion}

In this paper we presented a through literature review considering the area of web services supply chains and the need for QoS optimization in such supply chains. The gaps in various dimensions such as conceptual gap, QoS gap and the method gap are identified and pointed out. The current methods used, the QoS attributes considered and various other dimensions of the literature are classified and presented clearly for understanding the need for considering this new area of research. The defining of the characteristics, consolidation of QoS attributes for the web services supply chains and the mutual optimization of the same will be our future work.

\section{References:}

[1] Alonso, G; Fiedler, U; Hagen, C; Lazcano, A;Schuldt,H;Weiler,N, “WISE: Business to Business ECommerce", Research issues on data engineering information technology for virtual enterprises, May 1999, pp 132 - 139

[2] Wing Lam, “ Client - centered strategies for E-Commerce success, IEEE Journal of IT Professional, Sept/ Oct 1999, Vol : 1; issue : 5, pp 45

[3] Tom McGuffog, "E-Commerce and the value chain", IEEE seminar on rethinking manufacturing, May 1999, PP $157-160$

[4] Yan Wang; Kwei - Jay Lin, "Reputation - oriented trustworthy computing in E-Commerce environments, IEEE journal on Internet Computing, 2008, Vol : 12; issue : 4, pp 55 -59

[5] .Atif. Y, "Building trust in E- Commerce", IEEE journal on Internet Computing, Vol : 6; issue : 1 , 2002, pp $18-24$

[6] Qiu. R. G; Zhigang Fang; Ming yu; Jin Dong; Zhang Shen, “ Design and development of a service oriented supply chain: An IT perspective", 5th International Conference on Industrial Informatics, 2007, Vol : 1, pp 585 - 590 
[7] Moyaux,T; Chaib - Draa,B; D' Amours,S, “Information sharing as a co-ordination mechanism for reducing the bull whip effect in a supply chain", IEEE transactions on systems management and cybernatics, 2007, Vol : 37, issue : 3, pp $396-409$

[8] Hiu Hu; Davei Hu, "Study on intelligent collaboration mode of supply chain", IEEE conference on service operations and logistics and informatics, 2010, pp $205-207$

[9] Jun Lan; Laatikainen, M; Dijinkov, Y; Sinha ,D, “ How can supply chain collaboration contribute to a retail company's competitive strategy : The design of an empirical research", International conference on management and service science, 2009, pp 1-5

[10] Chituc ,C-M; Toscano ,C; Azevedo ,A, “E-Business and collaborative networks: A service oriented ICT platform for the foot wear industry", 5th International conference on industrial informatics, 2005, Vol : 1, pp $591-596$

[11] Michalako ,S; Anagnostopoulos ,A; Depasta ,C; Pramatari ,K, "Using web - services to support collaboration practices along the supply chain", International conference on next generation web service practices, 2005, pp 66

[12] http://www.cia.gov/library/publications/the-wroldfact book/geos/in.html

[13] Pierre.F.Tiako," Web services modeling fro E-Market place", Symposium on applications and the internet (SAINT) , 2003, pp 111

[14] Jiang Hu; Shekao Hu, " Analysis on the model of information sharing in the management of supply chain", International conference on management and service science, 2009, pp 1-3

[15] Gonçalo Cândidoa; José Barata; Armando Walter Colombo; François Jammes, "SOA in reconfigurable supply chains: A research road map", Journal of engineering applications of artificial intelligence, 2009, Vol : 22; issue : 6, pp 939 - 949

[16] Sanjeev kumar; Vijay Dakshinamoorthy; M.S. Krishnan, "Does SOA improve the supply chain? An empirical analysis of the impact of SOA adoption on electronic supply chain performance, "40th International conference on system sciences, 2007

[17] Huaqing Wu; Shu Yang, "Service supply chain : A conceptual framework compared with manufacturing supply chain", Conference on management and service sciences, 2009, pp 1-4

[18] Jos van Hillegersberg; Ruurd Boeke; Willem-Jan van den Heuvel, “ The potential of web services to enable smart business networks", Journal of information technology, 2004, Vol : 19, pp 281 - 287

[19] S.E.Sampson, "Customer - supplier duality in bi-directional supply chains in service organizations", International journal of service industry management, 2004, Vol : 11; issue : 4, pp $348-364$

[20] Nancy.K.Lankton; E.Vance Wilson, “ Antecedents and dimension of online service expectation”, IEEE transaction on Engineering management, 2007, pp 776 - 778

[21] Zhang, X; Prybutok, V,“A Consumer Perspective of e-Service Quality”, IEEE Transactions on Engineering Management, 2005, Vol : 52; issue : 4, pp 461-477

[22] Muhamed Sukkar, "A thesis presented to the University of Waterloo in fulfillment of the thesis requirement for the degree of Master of Mathematics in Computer Science", Ontario, Canada, 2010

[23] Munindar.P.Singh; Michael . N. Huhns, "Service oriented computing : Key concepts and principles", Journal on internet computing, 2005, Vol : 9; issue : 1, pp $75-81$

[24] Shuping Ran, "A Model for Web Service Discovery with QoS", ACM SIGecom Exchanges Volume 4 Issue 1,2003, pp $1-10$

[25] Yeom ,G; Yun ,T; Min ,D," A QoS Model and Testing Mechanism for Quality-driven Web services Selection", International Workshop on Collaborative Computing, Integration, and Assurance (SEUSWCCIA), 2006, pp 199 - 204

[26] N. Sato, K. Trivedi, "Accurate and efficient stochastic reliability of composite services", IEEE International conference on services computing, pp $114-121,2007$

[27] Zhang ,L; Zhang ,J, "Criteria analysis and validation of reliability for web service oriented systems", ICWS '05 Proceedings of the IEEE International Conference on Web Services, 2005

[28] Pathak, J., Basu, S., Honavar, V, "Modeling Web Services by Iterative Reformulation of Functional and Non-functional Requirements", International conference on service oriented computing ICSOC, LNCS 4294, pp. 314-326, 2006 
International Journal on Web Service Computing (IJWSC), Vol.3, No.1, March 2012

[29] Erradi ,A; Maheshwari ,P,” A Broker-based Approach for Improving Web Services Reliability”, IEEE International Conference on Web Services (ICWS), 2005

[30] Kirkham ,T; Varsamidis , T, "A Business Service Network to Aid Collaboration between Small to Medium Enterprises", 8th IEEE International Conference on E-Commerce Technology and The 3rd IEEE International Conference on Enterprise Computing, E-Commerce, and E-Services (CEC/EEE'), 2006.

[31] Tong ,H; Cao ,J; Zhang ,S; Mou ,Y, “A fuzzy evaluation system for web services selection using extended QoS model", Kybernetes, Vol. 38 Iss: 3/4, 2009, pp.513 - 521

[32] Wang ,L; Bai ,X; Zhou ,L, “A Hierarchical Reliability Model of Service-Based Software System”, 33rd Annual IEEE International Computer Software and Applications Conference, 2009, pp $198-208$

[33] Raimondi ,F; Skene ,J; Emmerich, W, “A Methodology for On-line Monitoring Non-Functional Specifications of Web-Services", Proceedings of the First International Workshop on Property Verification for Software Components and Services (PROVECS) ,2007, pp 50 - 59

[34] Li ,Y; Xiong ,A; Qi ,X, “A New Algorithm about QoS of Web Service”, 2nd IEEE International Conference on Information Management and Engineering (ICIME),2010, pp $521-523$

[35] Tran,VX;Tsuji ,H; Masuda ,R, "A new QoS ontology and its QoS-based ranking algorithm for Web services", Simulation Modelling Practice and Theory Vol 17, Issue 8, 2009, PP 1378-1398

[36] Rao ,J; Su ,X, “A Survey of Automated Web Service Composition Methods”, Semantic Web Services and Web Process Composition,2004, vol 3387, pp 43 - 54

[37] M. Tian, A. Gramm, H. Ritter, J. Schiller, R. Winter, "A Survey of current Approaches towards Specification and Management of Quality of Service for Web Services", PIK vol 27 no 3, 2004, pp $132-140$

[38] Galster ,M; Eva ,B, “A Taxonomy for Identifying and Specifying Non-functional Requirements in Service-oriented Development", IEEE Congress on Services, 2008, pp 345 - 352

[39] Hofner ,P; Lautenbacher ,F, "Algebraic Structure of Web Services”, Electronic Notes in Theoretical Computer Science 2000, PP 171-187

[40] Anja Strunk, "An Algorithm to Predict the QoS-Reliability of Service Compositions", IEEE 6th World Congress on Services, 2010, pp $205-212$

[41] Seo-Tsyr ,Y;Mei -Rung, L, "An value-centric event driven model and architecture: A case study of adaptive complement of SOA for distributed care service delivery", Expert Systems with Applications ,2009, Vol 36, Issue 2, Part 2,PP 3671-3694

[42] Hongyu Sun; Basu, S.; Honavar, V.; Lutz, R. , "Automata-Based Verification of Security Requirements of Composite Web Services" IEEE 21st International Symposium on Software Reliability Engineering (ISSRE) ,2010, pp 348 - 357

[43] D.A. Menasce, “Automatic QoS Control”, IEEE Computer society,2003, pp 92 - 96

[44] Jizi ,L; Ling, Y; Jun ,G, "Business Integrated Architecture for Dynamic Supply Chain Management with Web Service", IEEE International Conference on New Trends in Information and Service Science, 2009, pp $356-361$

[45] Gregoire, B.; Schmitt, M.;, "Business service network design: from business model to an integrated multi-partner business transaction", 3rd IEEE International Conference on Enterprise Computing, ECommerce and E-Services, 2006, pp 84 - 91

[46] Liu ,X; Zhu ,L, "DESIGN OF SOA BASED WEB SERVICE SYSTEMS USING QFD FOR SATISFACTION OF QUALITY OF SERVICE REQUIREMENTS", IEEE International Conference on Web Services, 2009, pp $567-574$

[47] Tian, M.; Gramm, A.; Ritter, H.; Schiller, J, "Efficient Selection and Monitoring of QoS-aware Web services with the WS-QoS Framework", IEEE/WIC/ACM International Conference on Web Intelligence WI, 2004, pp $152-158$

[48] Agarwal, V.; Jalote, P, "Enabling End-to-End Support for Non-Functional Properties in Web Services", IEEE International Conference on Service-Oriented Computing and Applications (SOCA), 2009 , pp 1-8 
International Journal on Web Service Computing (IJWSC), Vol.3, No.1, March 2012

[49] Badr, Y; Abraham,A; Biennier ,F; Grosan ,C , "Enhancing Web Service Selection by User Preferences of Non-Functional Features", 4th International Conference on Next Generation Web Services Practices NWESP, 2008.

[50] Del Val, E; Navarro ,M; Julian ,V;Rebollo ,M , "Ensuring time in service composition”, IEEE computer society Congress on Services 2009

[51] Sullivan ,J; Edmond ,D; Hofstede ,H.M , "Formal description of non-functional service properties", Centre for Information Technology Innovation Queensland University of Technology ,Business Process Management Group 2005

[52] Karhunen, H.; Eerola, A.; Jantti, M, "Improving Service Management in Supply Chains", International Conference on Service Systems and Service Management, 2006, vol 2, pp 1415 - 1420

[53] Salo ,J; Karjaluoto ,H , "IT_Enabled Supply Chain Management”, Contemporary Management Research , 2006, Vol. 2, No. 1, PP 17-30

[54] Zadeh ,M.H; Seyyedi ,M.A, “Qos Monitoring for Web Services by Time Series Forecasting”, 3rd IEEE International Conference on Computer Science and Information Technology (ICCSIT) ,2010.

[55] Wang ,P, "QoS-aware web services selection with intuitionistic fuzzy set under consumer's vague perception", Expert Systems with Applications, 2009, Vol 36, Issue 3, Part 1, PP 4460-4466

[56] Li ,Y; Wen ,T, "Quality and Relation Driven Service Selection for Web Services Composition”, 2009 International Conference on New Trends in Information and Service Science pp 152 - 155

[57] Erradi, A.; Maheshwari, P.; Tosic, V, "Recovery Policies for Enhancing Web Services Reliability", International Conference on Web Services, 2006. ICWS pp 189-196

[58] Kazhamiakin, R.; Pandya, P.; Pistore, M, "Representation, Verification, and Computation of Timed Properties in Web Service Compositions", International Conference on Web Services, 2006. ICWS pp $497-504$

[59] Kalepu, S.; Krishnaswamy, S.; Seng Wai Loke, "Reputation $=\mathrm{f}($ User Ranking, Compliance, Verity)", IEEE International Conference on Web Services, 2004, Proceedings pp $200-207$

[60] Carey, M.J, “SOA What?", IEEE Journal ,2008, Vol: 41 , Issue: 3 pp 92 - 94

[61] Mayerl, C.; Vogel, T.; Abeck, S , "SOA-based Integration of IT Service Management Applications", International Conference on Web Services, 2005, ICWS.

[62] Yu, T.; Lin, K.-J, “The Design of QoS Broker Algorithms for QoS-Capable Web Services”, IEEE International Conference on e-Technology, e-Commerce and e-Service, IEEE ,2004, pp 17 - 24

[63] Zhang ,X; Chen ,Y; Cao ,H, "The Discussion of Collaboration Management of Tourism Services Supply Chain", International Conference on Management and Service Science MASS, 2010, pp 1 - 4

[64] Kart, F.; Shen ,Z; Gerede, C.E , "The MIDAS System: A Service Oriented Architecture for Automated Supply Chain Management", IEEE International Conference on Services Computing SCC, 2006, pp $487-494$

[65] Liu ,R; Hu ,C; Zhao ,C;Gao ,Z, "Verification for Time Consistency of Web Service Flow", Seventh IEEE/ACIS International Conference on Computer and Information Science, ICIS 2008, pp 624 629

[66] Jughans ,M; Sudhir ,A, "Web Service Discovery Based on Unified View on Functional and NonFunctional Properties", IEEE Fourth International Conference on Semantic Computing, 2010, pp 224 $-227$

[67] Lamanna, D.D.; Skene, J.; Emmerich, W , "SLAng: a language for defining service level agreements", Proceedings of The Ninth IEEE Workshop on Future Trends of Distributed Computing Systems, 2003, FTDCS PP $100-106$

[68] Erradi, A.; Padmanabhuni, S.; Varadharajan, N , "Differential QoS support in Web Services Management", International Conference on Web Services, 2006, ICWS pp $781-788$

[69] Zhu ,L; Liu ,X, "Technical Target Setting in QFD for Web Service Systems Using an Artificial Neural Network", IEEE Transactions on Services Computing, 2010, vol 3, issue 4, pp 338 - 352

[70] Chan, A.T.S.; Jiannong Cao; Chan, C.K , "WEBGOP: collaborative web services based on graphoriented programming", IEEE Transactions on Systems, Man and Cybernetics, Part A: Systems and Humans, 2005, vol 35 , issue 6, pp $811-830$ 
International Journal on Web Service Computing (IJWSC), Vol.3, No.1, March 2012

[71] Kritikos, K.; Plexousakis, D , "Mixed-Integer Programming for QoS-Based Web Service Matchmaking", IEEE Transactions on Services Computing, 2009, vol 2, issue 2, pp 122 - 139

[72] Weider ,D; Rachana ,B ; Radhakrishna; Sumana ,P; Vijaya ,K , "Modeling the Measurements of QoS Requirements in Web Service Systems", SIMULATION, 2007; vol. 83, 1: pp. 75-91

[73] Xiong ,P.C; Fan ,Y; Zhou ,M , "Web Service Configuration Under Multiple Quality-of-Service Attributes", IEEE Transactions on Automation Science and Engineering, 2009 vol 6, issue 2, pp 311 $-321$

[74] Zhovtobryukh ,D, “A Petri Net-based Approach for Automated Goal-Driven Web Service Composition" SIMULATION,2007, vol. 83, 1: pp. 33-63.

[75] Conti, M.; Kumar, M.; Das, S.K.; Shirazi, B.A , "Quality of service issues in Internet Web services”, IEEE Transactions on Computers, 2002, vol 51, issue 6, pp $593-594$ 